\title{
Effect of lactulose on short-chain fatty acids and lactate production and on the growth of faecal flora, with special reference to Clostridium difficile
}

\author{
Y. ITO, H. MORIWAKI, Y. MUTO, N. KATO*, K. WATANABE* and K. UENO* ${ }^{*}$ \\ First Department of Internal Medicine and *Institute of Anaerobic Bacteriology, Gifu University School of \\ Medicine, 40 Tsukasa-machi, Gifu 500, Japan
}

\begin{abstract}
Lactulose exerts a beneficial effect on hepatic encephalopathy by decreasing toxic shortchain (iC4-nC6) fatty acid (isobutyrate, butyrate, isovalerate, valerate, isocaproate and caproate) production. However, the precise mechanism by which lactulose exerts this effect remains uncertain. This study investigated the effect of lactulose on faecal flora, particularly Clostridium difficile, which produces mostly iC4-nC6 fatty acids. An in-vitro faecal incubation system was used to estimate how lactulose influences production of short-chain (C2-nC6) fatty acids and lactate. Faecal specimens were collected from patients with liver cirrhosis, who carried $C$. difficile in the colon. Supplementation of lactulose along with blood in faecal specimens decreased iC4-nC6 fatty acids production and increased acetate and lactate production, resulting in increased faecal acidity. These changes were statistically significant when compared with supplementation by blood alone. Quantitative faecal culture demonstrated that lactulose supplementation suppressed the growth of $C$. difficile and Bacteroides spp. (B. fragilis group), iC4-nC6 fatty acids-producing organisms. These results suggest that decreased faecal levels of iC4-nC6 fatty acids after lactulose supplementation may be related to suppression of iC4-nC6 fatty acids-producing faecal organisms, especially $C$. difficile.
\end{abstract}

\section{Introduction}

Cerebrotoxic substances derived from the gut such as ammonia, short-chain fatty acids (SCFAs), mercaptans and $\gamma$-aminobutyric acids are thought to be responsible for hepatic encephalopathy (HE). While ammonia is most widely studied among these toxic substances, hyperammonaemia is not always associated with $\mathrm{HE}$. Increased blood levels of isobutyrate (iC4), butyrate (nC4), isovalerate (iC5), valerate (nC5), isocaproate (iC6) and caproate (nC6) in patients with $\mathrm{HE}$ [1] and induction of HE by these SCFAs in animals [2] have been reported.

Lactulose is a disaccharide ( $\beta$ 1-4 galacto-fructose) which has been used extensively since 1966 in the treatment of HE [3]. Taken orally, lactulose passes unchanged into the colon where it is hydrolysed by bacterial action to organic acids, principally acetate

Received 1 Dec. 1995; revised version accepted 21 June 1996.

Corresponding author: Dr Y. Ito.

$\nmid$ Present address: Gifu College of Medical Technology, Seki City, Gifu 501-32, Japan. and lactate. Although the precise mode of action of lactulose remains unclear, proposed mechanisms are: (i) lowering colonic $\mathrm{pH}$, thereby decreasing the production of ammonia by bacteria [4] and the absorption of non-ionised ammonia [5]; (ii) serving as substrate to increase the incorporation of ammonia into bacterial protein [6]; and (iii) decreasing the intestinal transit time available for production and absorption of ammonia because of its cathartic effect [7]. Mortensen et al. [8] showed that lactulose decreased the degradation of amino acids, albumin and blood to iC4-nC6 fatty acids by its acidifying effect.

The majority of SCFAs are produced by anaerobic bacteria that ferment dietary carbohydrates to SCFAs in the colon [9]. These bacteria include Clostridium spp., Bacteroides spp. (B. fragilis group), Fusobacterium spp. and Megasphaera spp. Among them, the Bacteroides spp. are one of the major components of intestinal flora, contributing to ammonia production but producing only a small amount of iC5. In contrast, $C$. perfringens produces a large amount of $\mathrm{nC} 4$ and $C$. difficile produces large amounts of $\mathrm{iC} 4-\mathrm{nC} 6$ fatty acids $[10,11]$. 
A previous study showed an overgrowth of $C$. difficile and $C$. perfringens in the faecal flora of patients with $\mathrm{HE}$, which was induced by administration of antimicrobial agents [12]. The rate of carriage of $C$. difficile was c. $20 \%$ in patients with liver cirrhosis (unpublished observations) and 7\% in healthy elderly adults [13]. Although these observations indicate that Clostridium spp. are of clinical importance in the development of $\mathrm{HE}$, the effect of lactulose on $C$. perfringens has been examined in only a few studies $[14,15]$ and no report has focused on $C$. difficile.

The aim of this study was to evaluate the effect of lactulose on the faecal levels of SCFAs and lactate as well as on the growth of intestinal flora, especially $C$. difficile, with an in-vitro faecal incubation system, where faecal specimens containing $C$. difficile were employed.

\section{Materials and methods}

\section{Patients}

Six inpatients with liver cirrhosis, who carried $C$. difficile, provided stool specimens. No antimicrobial agents had been prescribed during the 4 weeks prior to the study. Clinical characteristics and laboratory data on admission are shown in Table 1. Two patients had mild diarrhoea while others had normal faeces.

\section{Preparation of samples}

The in-vitro faecal incubation system was similar to that of Mortensen et al. [16]. Freshly passed faeces were homogenised with five volumes of $100 \mathrm{mM} \mathrm{NaCl}$ and $50 \mathrm{mM} \mathrm{KCl}$. Ten $\mathrm{ml}$ of faecal homogenates were mixed with one of the following; blood $(0.5 \mathrm{ml} / 10 \mathrm{ml}$ faecal homogenate), lactulose $(25 \mathrm{mmol} / \mathrm{L})$ and blood $(0.5 \mathrm{ml} / 10 \mathrm{ml}$ faecal homogenate $)$ or no addition. Each faecal sample was then incubated anaerobically at $37^{\circ} \mathrm{C}$ for $24 \mathrm{~h}$ in an atmosphere of $\mathrm{N}_{2} 80 \%, \mathrm{H}_{2} \quad 10 \%$ and $\mathrm{CO}_{2} \quad 10 \%$.

\section{Bacteriological examination}

One $\mathrm{ml}$ of the incubated faecal sample was homogenised with $9 \mathrm{ml}$ of anaerobic diluent, and serial 10 -fold dilutions were made to give a final dilution of $10^{7}$. Each odd number of logarithmic dilution was inoculated quantitatively onto the media shown in Table 2. Aerobic and anaerobic cultures were incubated at $37^{\circ} \mathrm{C}$ for $72 \mathrm{~h}$. The number of organisms was expressed as $\log _{10} \mathrm{cfu} / \mathrm{ml}$ of incubated faecal sample. Isolates were identified to genus level according to standard methods $[10,11,17]$.

\section{Determination of SCFAs and lactate in incubated faecal samples}

One $\mathrm{ml}$ of the incubated faecal sample was mixed with $0.1 \mathrm{ml}$ of $\mathrm{H}_{2} \mathrm{SO}_{4} 50 \%$ and $1 \mathrm{ml}$ of diethyl ether, and centrifuged briefly to make an ether extract for the determination of SCFAs - acetate (C2), propionate (C3), iC4, nC4, iC5, nC5, iC6 and nC6 [10]. For the determination of lactate, a mixture of $1 \mathrm{ml}$ of the incubated faecal sample, $0.1 \mathrm{ml}$ of $\mathrm{H}_{2} \mathrm{SO}_{4} 50 \%$ and $1 \mathrm{ml}$ of $\left(\mathrm{CH}_{3} \mathrm{OH}\right)_{2} \mathrm{BF}_{3}$ was heated at $100^{\circ} \mathrm{C}$ for $5 \mathrm{~min}$

Table 2. Media for the isolation of aerobic and anaerobic bacteria from faecal samples

\begin{tabular}{ll}
\hline Medium & Selectivity \\
\hline Anaerobic & \\
Modified GAM agar* & Non-selective \\
CCMA agar* & C. difficile \\
Kanamycin CW egg-yolk agar* & C. perfringens \\
Modified FM agar* & Fusobacterium spp. \\
BL blood agar* & Bifidobacterium spp. \\
LBS agar ${ }^{\dagger}$ & Lactobacillus spp. \\
BBE agar & Bacteroides spp. \\
PMS blood agar & Megasphaera spp. \\
Aerobic & \\
TSA blood agar* & Non-selective \\
DHL agar* & Enterobacteriaceae \\
\hline
\end{tabular}

*Nissui Pharmaceutical Co. Ltd.

${ }^{\dagger}$ BBL Microbiology Systems.

${ }^{\ddagger}$ Kyokuto Pharmaceutical Industries Co. Ltd.

${ }^{\S} \mathrm{EG}$ agar (Nissui) supplemented with PMS $1 \%$ solution (70 mg crystal violet and $50 \mathrm{mg}$ achromycin were dissolved in distilled water to make $100 \mathrm{ml}$ of PMS solution).

Table 1. Clinical characteristics and laboratory data of six patients studied

\begin{tabular}{|c|c|c|c|c|c|c|c|}
\hline Parameter & Normal range & Case 1 & Case 2 & Case 3 & Case 4 & Case 5 & Case 6 \\
\hline Age & $\ldots$ & 64 & 65 & 67 & 61 & 78 & 64 \\
\hline Sex & $\ldots$ & Male & Male & Male & Male & Female & Male \\
\hline $\mathrm{TP}$ & $(63-82 \mathrm{~g} / \mathrm{Q})$ & 72 & 94 & 75 & 56 & 52 & 55 \\
\hline Albumin & $(37-50 \mathrm{~g} / \mathrm{Q})$ & 26 & 22 & 21 & 21 & 25 & 21 \\
\hline TB & $(6.8-20.5 \mu \mathrm{mol} / \mathrm{Q})$ & 23.9 & 99.2 & 128.3 & 58.1 & 44.5 & 37.6 \\
\hline GOT & $(0.08-0.58 \mu \mathrm{kat} / \mathrm{Q})$ & 1.70 & 3.08 & 1.88 & 7.83 & 0.75 & 1.58 \\
\hline GPT & $(0.08-0.58 \mu \mathrm{kat} / \mathrm{Q})$ & 0.98 & 1.70 & 0.88 & 2.87 & 0.35 & 1.25 \\
\hline PT & $(10.0-14.0 \mathrm{~s})$ & 15.0 & 21.9 & 22.1 & 15.0 & 17.7 & 14.2 \\
\hline BUN & $(3.0-7.5 \mathrm{mmol} / \mathrm{Q})$ & 19.1 & 32.9 & 7.2 & 15.1 & 4.3 & 11.5 \\
\hline Creatinine & $(35-97 \mu \mathrm{mol} / \mathrm{Q})$ & 141 & 283 & 53 & 177 & 53 & 80 \\
\hline Ammonia & $(<44 \mu \mathrm{mol} / \mathrm{Q})$ & 21 & 39 & 48 & 10 & 64 & 58 \\
\hline HBsAg & $\ldots$ & - & - & - & - & - & - \\
\hline HCVAb & $\ldots$ & + & - & + & + & + & + \\
\hline Defaecation/day & $\ldots$ & 4 & 3 & 1 & 3 & 2 & 4 \\
\hline Form of stool & $\ldots$ & Soft & Normal & Normal & Soft & Normal & Normal \\
\hline
\end{tabular}

TP, total protein; TB, total bilirubin; GOT, glutamate oxaloacetate transaminase; GPT, glutamate pyruvate transaminase; PT, prothrombin time; BUN, blood urea nitrogen; HBsAg, hepatitis B surface antigen; HCVAb, hepatitis C antibody; +, positive; -, negative. All cases were diagnosed as liver cirrhosis with hepatocellular carcinoma. 
and centrifuged briefly with $1 \mathrm{ml}$ of chloroform to make a chloroform extract. These extracts were subjected to gas-liquid chromatography (Shimadzu GC-14A, Shimadzu Corp., Kyoto, Japan) with a $1.6 \mathrm{~m} \times 3.2-\mathrm{mm}$ column packed with Reoplex 400 $10 \%$ on Chromosorb W(AW-PMCS) (80-100 mesh). Gas flows were $50 \mathrm{ml} / \mathrm{min}$ for $\mathrm{N}_{2}, 50 \mathrm{ml} / \mathrm{min}$ for $\mathrm{H}_{2}$ and $1000 \mathrm{ml} / \mathrm{min}$ for air. Temperatures were kept at $150^{\circ} \mathrm{C}$ for the column and $220^{\circ} \mathrm{C}$ for the injector and the flame-ionisation detector.

\section{Production of SCFAs and lactate by isolates from faeces}

A standard loopful of isolate was inoculated into Gifu Anaerobic Medium (GAM) broth [18] (Nissui Pharmaceutical Co., Ltd) and incubated anaerobically at $37^{\circ} \mathrm{C}$ for 3-4 days. SCFAs and lactate production were determined as described above.

\section{pH analysis}

The $\mathrm{pH}$ of incubated faecal samples was measured with pH test paper $\left(\right.$ Advantec $^{\mathbb{R}}$, Toyo Roshi Co. Ltd, Tokyo, Japan).

\section{Statistical methods}

All comparisons were performed by paired $t$ test with Statview software (Abacus Concepts Inc., Berkeley, CA, USA).

\section{Results}

SCFAs and lactate levels in incubated faecal samples

Following incubation, the faecal samples of all six individuals showed production of $\mathrm{C} 2-\mathrm{nC} 6$ fatty acids. The addition of blood increased acetate, iC4-nC6 and lactate production while addition of lactulose extinguished the effect of blood on iC4-nC6 fatty acids production and increased faecal levels of acetate and lactate (Table 3). A marked decrease in faecal $\mathrm{pH}$ was observed following the addition of lactulose.

\section{Changes in faecal flora}

The growth of $C$. difficile, Bacteroides spp., Bifidobacterium spp. and Enterobacteriaceae was significantly suppressed by the addition of lactulose, while growth of $C$. perfringens was not suppressed (Table 4).

Table 3. Effect of lactulose and blood on production of short-chain fatty acids and lactate, and $\mathrm{pH}$ values in six incubated faecal samples

\begin{tabular}{lcccc}
\hline \multirow{2}{*}{$\begin{array}{l}\text { Supplement } \\
\text { to faecal }\end{array}$} & Mean (SD) & \multicolumn{3}{c}{ Mean (SD) concentration (mmol/L) } \\
\cline { 3 - 5 } specimen & $\mathrm{pH}$ value & acetate & iC4-nC6 & lactate \\
\hline None & $6.2(0.2)$ & $24.55(13.77)$ & $7.22(5.79)$ & ND \\
Blood & $6.3(0.2)$ & $32.62(12.30)^{*}$ & $13.23(7.61)^{*}$ & $1.70(1.72)$ \\
Blood + lactulose & $3.9(0.3)^{\dagger}$ & $75.20(42.61)^{\dagger}$ & $2.53(1.18)^{\dagger}$ & $109.58(74.20)^{\dagger}$ \\
\hline
\end{tabular}

$\mathrm{iC} 4-\mathrm{nC} 6=$ sum of $\mathrm{iC} 4, \mathrm{nC} 4, \mathrm{iC} 5, \mathrm{nC} 5, \mathrm{iC6}$ and $\mathrm{nC} 6 . \mathrm{iC} 4$, isobutyrate; nC4, butyrate; iC5, isovalerate; nC5, valerate; ic6, isocaproate; $\mathrm{nC6}$, caproate. N.D., not detectable.

${ }^{*} \mathrm{p}<0.05$ versus medium without supplement.

${ }^{\dagger} \mathrm{p}<0.05$ versus blood.

${ }_{\mathrm{p}}<0.001$ versus blood.

Table 4. Effect of lactulose and blood on the composition of faecal flora

\begin{tabular}{|c|c|c|c|}
\hline \multirow[b]{2}{*}{ Organism } & \multicolumn{3}{|c|}{$\begin{array}{c}\text { Mean (SD) } \log _{10} \mathrm{cfu} / \mathrm{ml} \text { and frequency of occurrence }() \text { in } \\
\text { faecal specimen supplemented with }\end{array}$} \\
\hline & No supplement & Blood & Blood + lactulose \\
\hline Total anaerobes & $9.3 \mathrm{SD} 0.5(6 / 6)$ & $9.4 \mathrm{SD} 0.4(6 / 6)$ & $8.8 \mathrm{SD} 1.2(6 / 6)$ \\
\hline C. difficile & 5.5 SD $1.8(6 / 6)$ & $6.1 \mathrm{SD} 1.3(6 / 6)$ & $3.2 \mathrm{SD} \quad 0.8^{\ddagger}(5 / 6)$ \\
\hline C. perfringens & $5.2 \mathrm{SD} 1.8(5 / 6)$ & $5.2 \mathrm{SD} 2.0(5 / 6)$ & $5.0 \mathrm{SD} 1.9 \quad(5 / 6)$ \\
\hline B. fragilis group & 8.6 SD $0.8(6 / 6)$ & $8.8 \mathrm{SD} 0.5(6 / 6)$ & $3.7 \mathrm{SD} 2.0^{\dagger}(4 / 6)$ \\
\hline Fusobacterium spp. & $2.5 \mathrm{SD} 1.2(1 / 6)$ & $2.5 \mathrm{SD} 1.2(1 / 6)$ & $\mathrm{ND}^{*}$ \\
\hline Megasphaera spp. & $\mathrm{ND}^{*}$ & $\mathrm{ND}^{*}$ & $\mathrm{ND}^{*}$ \\
\hline Bifidobacterium spp. & 7.7 SD $2.9(5 / 6)$ & 7.7 SD $2.9(5 / 6)$ & $\mathrm{ND}^{\dagger}$ \\
\hline Total aerobes & 8.6 SD $0.4(6 / 6)$ & $8.9 \mathrm{SD} 0.5(6 / 6)$ & $8.5 \mathrm{SD} 0.5 \quad(6 / 6)$ \\
\hline Lactobacillus spp. & $7.7 \mathrm{SD} 1.0(6 / 6)$ & $7.8 \mathrm{SD} 1.1(6 / 6)$ & $8.3 \mathrm{SD} 0.7 \quad(6 / 6)$ \\
\hline Enterobacteriaceae & 6.7 SD $2.1(6 / 6)$ & 7.0 SD $1.9(6 / 6)$ & $2.3 \mathrm{SD} 0.7^{\dagger}(1 / 6)$ \\
\hline
\end{tabular}

Figures in parentheses are frequency of occurrence (number of subjects yielding the organisms/ number of subjects examined).

*ND (not detectable) is calculated as 2.0

${ }^{\dagger} \mathrm{p}<0.01$ versus blood.

${ }_{\mathrm{p}}^{\mathrm{p}}<0.001$ versus blood. 
Lactobacillus spp. became the major component after lactulose was added to faecal samples.

\section{SCFAs and lactate production by faecal isolates}

Bacteroides isolates produced iC5, Fusobacterium and $C$. perfringens isolates produced $\mathrm{nC} 4$, while $C$. difficile isolates produced $\mathrm{iC} 4-\mathrm{nC} 6$ fatty acids.

\section{Discussion}

Although the precise mode of action of lactulose has not been clarified, one of the speculated mechanisms is the acidification of the colon contents by fermented products of lactulose. Mortensen et al. [16] showed that iC4-nC6 fatty acid production by faecal flora was increased by the addition of blood, albumin and amino acids but decreased by adding lactulose in vitro. They initially suggested that this effect was the result of substrate competition, i.e., colonic bacteria preferred lactulose to blood when both were present. Later it was reported that the acidifying effect of lactulose was more important in decreasing $\mathrm{iC} 4-\mathrm{nC} 6$ fatty acids production [8].

The present study confirmed that the addition of lactulose decreased faecal levels of iC4-nC6 fatty acids, increased acetate production and reduced faecal $\mathrm{pH}$. It further demonstrated that lactulose caused an increase in lactate production in the faecal incubation system, which contributed to an increase in faecal acidity. Of particular importance was the finding that the growth of both $C$. difficile (mostly iC4-nC6 fatty acid-producing) and Bacteroides spp. (iC5-producing) was suppressed by lactulose.

The growth of $C$. difficile is particularly susceptible to changes in colonic acidity [19]. Rolfe et al. [20] showed that, in vitro, Lactobacillus spp. and group D enterococci produced large amounts of lactate that inhibited the growth of $C$. difficile. They also suggested that SCFAs played an important role in the induction of colonisation resistance against $C$. difficile in a conventional hamster model [21]. The invitro study by May et al. [22] suggested that acidification with SCFAs produced by fermentation of dietary fibre suppressed $C$. difficile.

The study data can be interpreted as follows: acidification with acetate and lactate produced by fermentation of lactulose suppressed faecal anaerobes, especially $C$. difficile, resulting in a decrease of $\mathrm{iC} 4-$ nC6 fatty acids production.

Others have reported the effect of oral lactulose on human faecal flora in vivo. An increase in Lactobacillus and Bifidobacterium spp. and a decrease in Bacteroides spp. and coliform organisms (Enterobacteriaceae) were noted $[15,23]$. These in-vivo findings are similar to the in-vitro results of the present study except for Bifidobacterium spp. The conflicting Bifidobacterium spp. data seem to result from a difference in environmental $\mathrm{pH}$. The $\mathrm{pH}$ in the right colon decreases to 4.85 after ingestion of lactulose [24], whereas the $\mathrm{pH}$ was below 4 in the in-vitro faecal incubation system. As reported by Vince et al. [6], when the $\mathrm{pH}$ was uncontrolled and acidic conditions developed, Bifidobacterium spp. were suppressed by the addition of lactulose to samples. In any event, the action of lactulose in increasing the number of acid (lactate and/or acetate)-producing bacteria such as L. acidophilus, Enterococcus spp. or Bifidobacterium spp. seems to be important. Administration of these bacteria was shown to have an effect on HE [25-27].

Furthermore, a poorly absorbed disaccharide, lactitol, which was shown to improve HE, induces colonic acidification to a similar degree to lactulose [28]. Oligosaccharides taken orally significantly increased the number of Bifidobacterium spp. in human faecal flora [29]. Dietary fibre, which escapes from host digestion and is fermented to acetate, propionate and butyrate in the colon [9], was shown to increase the number of acid-producing bacteria but decrease the number of $C$. difficile and resultant toxin [22]. A vegetable protein diet supplemented with dietary fibre was also effective in HE [30]. In addition to lactulose, these substances may also exert a beneficial effect on HE by suppressing the growth of the $\mathrm{iC} 4-\mathrm{nC} 6$ fatty acids-producing organisms, $C$. difficile and Bacteroides spp., through colonic acidification. Further invivo studies are needed to establish the mechanisms of action of these substances.

We thank Dr G. E. Killgore, Centers for Disease Control and Prevention, for reviewing this manuscript.

\section{References}

1. Muto Y. Clinical study on the relationship of short-chain fatty acids and hepatic encephalopathy. Jpn J Gastroenterol 1966; 63: $19-32$.

2. Muto Y, Takahashi Y, Kawamura H. Effect of short-chain fatty acids on the electrical activity of neo-, paleo-, and archicortical systems. Brain Nerve 1964; 16: 601-608.

3. Bircher J. Müller J, Guggenheim P, Haemmerli UP. Treatment of chronic portal-systemic encephalopathy with lactulose. Lancet 1966; 1: 890-893.

4. Vince A, Dawson AM, Park N, O'Grady F. Ammonia production by intestinal bacteria. Gut 1973; 14: 171-177.

5. Castell DO, Moore EW. Ammonia absorption from the human colon. The role of nonionic diffusion. Gastroenterology 1971; 60: $33-42$.

6. Vince A, Killingley M, Wrong OM. Effect of lactulose on ammonia production in a faecal incubation system. Gastroenterology 1978; 74: 544-549.

7. Agostini L, Down PF, Murison J, Wrong OM. Faecal ammonia and $\mathrm{pH}$ during lactulose administration in man: comparison with other cathartics. Gut 1972; 13: 859-866.

8. Mortensen $\mathrm{PB}$, Holtug $\mathrm{K}$, Bonnén $\mathrm{H}$, Clausen MR. The degradation of amino acids, proteins, and blood to short-chain fatty acids in colon is prevented by lactulose. Gastroenterology 1990; 98: 353-360.

9. Wolin MJ. Control of short chain volatile acid production in 
the colon. In: Binder $\mathrm{HJ}$, Cummings $\mathrm{JH}$, Soergel $\mathrm{KH}$ (eds) Short chain fatty acids. Proceedings of the 73rd Falk Symposium. Dordrecht, Kluwer Academic Publishers. 1994: $3-10$.

10. Holdeman LV, Moore WEC, Cato EP. Anaerobe laboratory manual, 4th edn. Blacksburg, Virginia, Virginia Polytechnic Institute and State University. 1977.

11. Sneath PHA, Mair NS, Sharpe ME et al. Bergey's Manual of systematic bacteriology, vol 2. Baltimore, Williams \& Wilkins. 1986.

12. Ito $\mathrm{Y}$, Nakamura $\mathrm{T}$, Saito $\mathrm{K}$ et al. Pathophysiological role of intestinal flora in the development of hepatic encephalopathy, with special reference to floral alterations induced by antimicrobial agents. Micob Ecol Health Dis 1992; 5: 1-13.

13. Nakamura S, Mikawa $M$, Nakashio $S$ et al. Isolation of Clostridium difficile from the feces and the antibody in sera of young and elderly adults. Microbiol Immunol 1981; 25: 345351.

14. Kiyosawa I, Takase M, Yamauchi K. Lactulose and intestinal microfiora infant nutrition. Bifidobacteria Microflora 1986; 5 27-35.

15. Terada A, Hara H, Kataoka M, Mitsuoka T. Effect of lactulose on the composition and metabolic activity of the human faecal flora. Microb Ecol Health Dis 1992; 5: 43-50.

16. Mortensen PB, Rasmussen HS, Holtug K. Lactulose detoxifies in vitro short-chain fatty acid production in colonic contents induced by blood: implications for hepatic coma. Gastroenterology 1988; 94: 750-754.

17. Krieg NR, Holt JG (eds). Bergey's Manual of systematic bacteriology, vol 1. Baltimore, Williams \& Wilkins. 1984

18. Muto Y, Bandoh K, Watanabe K, Katoh N, Ueno K. Macrolide accumulation by Bacteroides fragilis ATCC 25285. Antimicrob Agents Chemother 1989; 33: 242-244.

19. Borriello SP, Barclay FE. An in-vitro model of colonisation resistance to Clostridium difficile infection. $J$ Med Microbiol 1986; 21: 299-309.
20. Rolfe RD, Helebian S, Finegold SM. Bacterial interference between Clostridium difficile and normal fecal flora. J Infect Dis 1981; 143: 470-475.

21. Rolfe RD. Role of volatile fatty acids in colonization resistance to Clostridium difficile. Infect Immun 1984; 45: 185-191.

22. May T, Mackie RI, Fahey GC, Cremin JC, Garleb KA. Effect of fiber source on short-chain fatty acid production and on the growth and toxin production by Clostridium difficile. Scand $J$ Gastroenterol 1994; 29: 916-922.

23. Conn HO, Lieberthal MM. Mechanisms of action of lactulose. In: The hepatic coma syndromes and lactulose. Baltimore, Williams \& Wilkins. 1979: 278-294.

24. Bown RL, Gibson JA, Sladen GE, Hicks B, Dawson AM. Effect of lactulose and other laxatives on ileal and colonic $\mathrm{pH}$ as measured by radiotelemetry device. Gut 1974; 15: $999-$ 1004 .

25. Macbeth WAAG, Kass EH, McDermott WV. Treatment of hepatic encephalopathy by alteration of intestinal flora with Lactobacillus acidophilus. Lancet 1965; 1: 399-403.

26. Loguercio C, Del Vecchio Blanco C, Coltori M. Enterococcus lactic acid bacteria strain SF68 and lactulose in hepatic encephalopathy: a controlled study. $J$ Int Med Res 1987; 15: $335-343$.

27. Sugawara N. The fecal microflora of cirrhotic patients and the therapy of hyperammonemia. J Tokyo Wom Med Coll 1992; 62: $1586-1597$.

28. Patil DH, Westaby D, Mahida YR et al. Comparative modes of action of lactitol and lactulose in the treatment of hepatic encephalopathy. Gut 1987; 28: 255-259.

29. Hayakawa K, Mizutani J, Wada K, Masai T, Yoshihara I, Mitsuoka T. Effect of soybean oligosaccharides on human faecal flora. Microb Ecol Health Dis 1990; 3: 293-303.

30. Uribe M, Dibildox M, Malpica S et al. Beneficial effect of vegetable protein diet supplemented with psyllium plantago in patients with hepatic encephalopathy and diabetes mellitus. Gastroenterology 1985; 88: 901-907. 